\title{
Argentine stem weevil damage to high sugar ryegrass infected with AR1 under field conditions
}

\author{
R.H. BRYANT ${ }^{1}$, A.J. PARSONS ${ }^{2}$, S. RASMUSSEN ${ }^{2}$ and G.R. EDWARDS ${ }^{1}$ \\ Agriculture and Life Sciences Division, PO Box 84, Lincoln University, Canterbury \\ AgResearch Grasslands Research Centre, PO Box 11008, Palmerston North
}

bryantr@lincoln.ac.nz

\begin{abstract}
Previous laboratory based studies indicate that, compared to standard cultivars, high sugar grasses (HSG) can have lower endophyte and peramine concentrations and suggest that $\mathrm{N}$ fertilisation may result in further reductions in endophyte and alkaloid. This could reduce the resistance of $\mathrm{HSG}$, particularly at high $\mathrm{N}$ inputs, to Argentine stem weevil (ASW), but the interaction needs testing under field conditions. The present objective was to determine the effect of ryegrass cultivar on ASW damage, and possible interactions with $\mathrm{N}$ fertiliser. ASW damage, endophyte and peramine concentration were measured in three perennial ryegrass cultivars, (HSG diploid, standard diploid and a tetraploid) containing AR1 endophyte, under high and no $\mathrm{N}$ fertiliser application. The proportion of tillers damaged by ASW adults or larvae did not differ significantly between cultivars. However, ASW adults tended $(\mathrm{P}<0.10)$ to prefer the standard diploid and tetraploid cultivars over the HSG cultivar. Our results are in keeping with previous observations that higher sugar diploid cultivars may have lower endophyte and peramine content than a STD diploid cultivar, but this does not appear to have reduced resistance to ASW. Lack of differences in N content of herbage leaves, between the $\mathrm{N}$ fertiliser treatments, likely due to compensating changes in clover content of pastures, meant little effect of $\mathrm{N}$ application was seen in this field trial.
\end{abstract}

Keywords: Lolium, Listronotus bonariensis, invertebrates, water soluble carbohydrates, ploidy

\section{Introduction}

The ability of perennial ryegrass to withstand attack by insects such as Argentine stem weevil (Listronotus bonariensis), particularly during dry summers, has a significant impact on subsequent persistence and productivity of pastures. That ability is largely dependent on the presence and type of endophyte associated with the plant. The development of novel endophytes such as AR1 which maintains the ability to deter insects through the production of the alkaloid peramine without the associated health risks caused by lolitrem B and ergovaline (Rowan 1993) have resulted in its widespread adoption throughout New Zealand.

The mechanism for the relationship between host, fungus and environment are still not well understood but there is increasing evidence that complex interactions do occur. Endophyte infection can alter source:sink relations in the host grass (Cheplick 2007). On the other hand, the host's physiology can also influence the endophyte. A recent example of such an interaction was revealed in a laboratory study by Rasmussen et al. (2006) who showed that when AR1 was inoculated into ryegrass selected for high water soluble carbohydrates, the concentration of total endophyte DNA in the lamina was significantly reduced by $50 \%$ compared to that of a standard cultivar infected with the same endophyte. At higher nitrogen status in the grass host, endophyte concentration was reduced by $75 \%$. In all cases the reduction in endophyte was associated, linearly, with a reduction in alkaloid concentration. Peramine is the single major known alkaloid produced in the AR1 endophyte and believed to be the host's major defence against ASW attack. The implications of the low concentrations of peramine in high sugar grasses were addressed by Edwards et al. (2007) who expressed concern over pasture productivity of high sugar grasses in pest prone areas. Because application of N-based fertilisers such as urea in spring is common practice, they emphasised the need for field trials to confirm the cultivar $\mathrm{x}$ endophyte $\mathrm{x} \mathrm{N}$ interactions. Consequently a field experiment containing high sugar and standard perennial ryegrass, both infected with AR1, was established to a) determine if expression of high sugar trait in the field resulted in reduced endophyte and peramine concentrations, $\mathrm{b}$ ) whether $\mathrm{N}$ application resulted in further reductions in endophyte and c) to what extent these results affected susceptibility to ASW feeding. A tetraploid cultivar, also likely to have a high sugar content, was included for comparison.

\section{Materials and Methods}

The impact of Argentine stem weevil (ASW) was determined on rotationally grazed plots at Lincoln University (Wakanui silt loam, $\mathrm{pH}=5.8$ and Olsen $\mathrm{P}=25$ ). Three AR1 infected perennial ryegrass cultivars: Aberdart-HSG (high sugar grass diploid); Samson-STD (standard diploid), and Quartet-4N (tetraploid) were each sown, along with white clover, (plots size $=25 \mathrm{~m}^{2}$ ) on 15 December 2006. Swards were replicated across three blocks which were split two ways receiving either no 
nitrogen after sowing or an annual application of $160 \mathrm{~kg}$ $\mathrm{N} / \mathrm{ha}$. At sowing all plots received $50 \mathrm{~kg} \mathrm{~N} / \mathrm{ha}$ in the form of urea. After sowing, the low $\mathrm{N}$ treatment received $0 \mathrm{~kg} \mathrm{~N}$ and the high $\mathrm{N}$ treatment received four applications of $40 \mathrm{~kg} \mathrm{~N} / \mathrm{ha}$ in February, April, September and December 2007 (160 kg N/ha/yr). Sheep were used to control pasture mass followed by topping to a uniform post-grazing height of $6 \mathrm{~cm}$.

The findings of a five year study of the ASW life cycle by Goldson et al. (1998) were used to select sampling dates for ASW damage. In an attempt to coincide with the feeding of 'second stage' larvae, the first assessment of ASW damage was carried out in March 2007. The second assessment was carried out in January 2008 to coincide with the feeding of the subsequent new population of 'first-stage' larvae. Tillers were collected by removing 3-5 cores per plot by cutting below the soil surface. Twenty tillers were taken at random to estimate insect damage. Damage caused by adults and larvae was recorded using the scoring system described by Popay et al. (2003) where adults feeding on lamina were scored on a scale of 0 (no feeding scars) to 5 (numerous feeding scars) and larvae feeding on pseudostem on a points basis of $0=$ no feeding, $1=$ minor (single hole without permanent damage) $2=$ moderate damage or $3=$ severe damage causing tiller death.

During the trial period, water soluble carbohydrate and nitrogen content of cultivars was determined on lamina (leaf blade) samples collected prior to each grazing in April, June, September, October, December 2007 and February 2008. Samples were collected between 13001400 hours and immediately frozen for subsequent freeze drying and grinding. Water soluble carbohydrate (WSC) and $\mathrm{N}$ content was estimated on freeze dried material by near infrared spectrophotometry (NIRS). Lamina samples were collected for peramine and endophyte analysis and clover composition was determined from quadrat cuts $\left(0.2 \mathrm{~m}^{2}\right)$ at the end of the rotational grazing regrowth periods in which ASW damage was measured (April 2007 and February 2008).

Infection by endophyte was initially confirmed in 30 tillers per cultivar 4 months after sowing by staining sections of sheath with aniline blue for 1-3 minutes. The presence or absence of mycelium was detected at x 400 magnification. Thereafter, the concentration of endophyte was analysed by quantitative PCR (q-PCR) using the technique described by Rasmussen et al. (2006) and peramine concentration analysed by HPLC (see also Rasmussen et al. 2006). The purpose of quantifying endophyte concentration was to determine if differences in peramine levels between cultivars grown in the field were the result of variation in the amount of endophyte present, or alkaloid production per unit endophyte.

Analysis of variance was performed on untransformed data using GenStat 9.0 using a split-plot design, with three blocks split into two nitrogen treatments, each containing all cultivars. The mean feeding score of total

Figure 1 Annual variation in water soluble carbohydrate (WSC) composition as estimated by NIRS of three perennial ryegrass cultivars under high and low nitrogen fertilisation. Vertical lines on $x$-axis indicate $\mathrm{N}$ application dates.

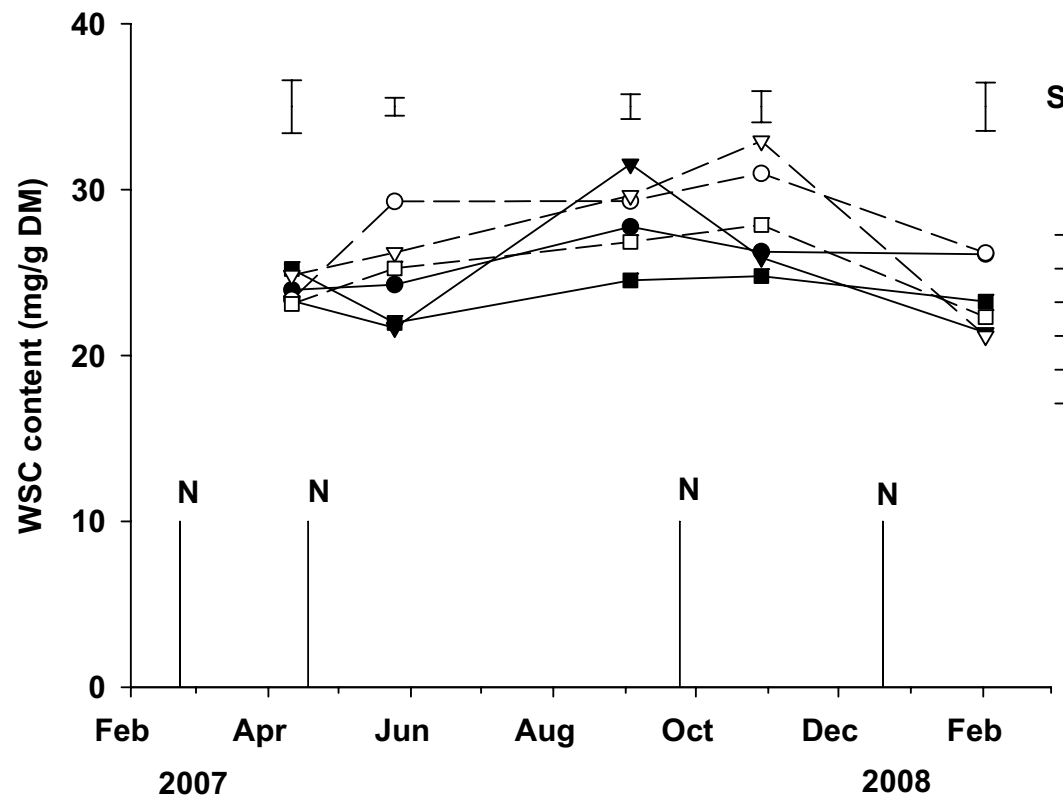


damaged tillers was analysed for variance as an unbalanced design using GenStat regression.

\section{Results}

\section{WSC and $N$ content}

Over the duration of the trial, WSC content of cultivars fluctuated between 173 and $340 \mathrm{mg} / \mathrm{g}$ DM (Fig. 1) but across dates Aberdart-HSG was, on average, significantly higher $(\mathrm{P}<0.05)$ than Samson-STD (267 vs. $245 \pm 6.2$ $\mathrm{mg} \mathrm{WSC/g} \mathrm{DM} \mathrm{respectively),} \mathrm{but} \mathrm{similar} \mathrm{to} \mathrm{Quartet-4N}$ (259 mg WSC/g DM). Water soluble carbohydrates were $7 \%$ lower under a high $\mathrm{N}$ fertiliser application regime (248 vs. 266 mg WSC/g DM; $\mathrm{P}<0.05$ ). Average N content for the period was $2.96 \% \mathrm{~N}$ under the high $\mathrm{N}$ treatment and $2.67 \% \mathrm{~N}$ under low $\mathrm{N}(\mathrm{P}<0.05$, Fig. 2) with no significant differences between cultivars. However, at the two autumn sampling dates, $\mathrm{N}$ content was similar for both treatments $(3.0$ and $2.2 \% \mathrm{~N}$ on March 2007 and February 2008 respectively). Clover content did not differ for $\mathrm{N}$ treatment groups in March
2007, and made up less than $3 \%$ of the sward, but by February 2008, clover content was $24.6 \%$ in the low N treatment and $9.6 \%$ in the high $\mathrm{N}$ treatment $(\mathrm{P}=0.057)$, possibly explaining the lack of difference in grass $\mathrm{N}$ content by this time.

\section{Endophyte and peramine concentration}

The initial endophyte infection rate of tillers, as determined by staining, was $90 \%$ for all three cultivars. However, in both years the concentration of endophyte (based on copies of fungal DNA per unit total DNA, assessed by q-PCR) was lower in Aberdart-HSG, compared to Samson-STD, although the difference between the three cultivars was significant only in 2008 (Table 1). The concentration of peramine in AberdartHSG in both 2007 and 2008 was significantly lower than in Samson-STD. At the time of sampling there were no significant effects of $\mathrm{N}$ treatment on endophyte or peramine levels, likely due to the lack of difference in how the $\mathrm{N}$ treatments affected herbage $\mathrm{N}$ content, in this

Figure 2 Annual variation in nitrogen $(\mathrm{N})$ composition as estimated by NIRS of three perennial ryegrass cultivars under high and low nitrogen fertilisation. Vertical bars on $x$-axis indicate $\mathrm{N}$ application dates.

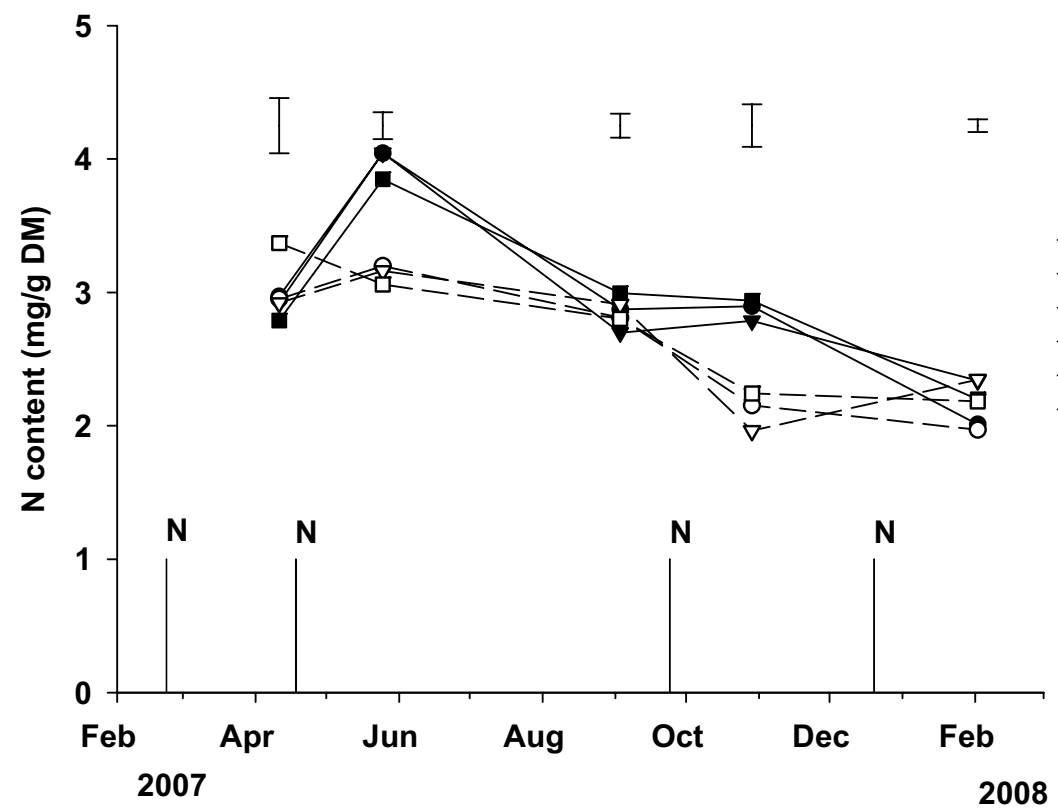

Table 1 Peramine and endophyte concentration in perennial ryegrass cultivars infected with AR1 endophyte.

\begin{tabular}{|c|c|c|c|c|}
\hline & $\begin{array}{l}\text { Ma } \\
\text { Endophyte } \\
\text { (copies DNA) }\end{array}$ & $\begin{array}{c}\text { Peramine } \\
(\mathrm{ppm})\end{array}$ & $\begin{array}{c}\text { Jan } \\
\text { Endophyte } \\
\text { (copies DNA) }\end{array}$ & $\begin{array}{c}\text { Peramine } \\
(\mathrm{ppm})\end{array}$ \\
\hline Aberdart-HSG & 29.4 & $17.9^{b}$ & $28.4^{\mathrm{b}}$ & $18.3^{b}$ \\
\hline Samson-STD & 34.4 & $27.2^{\mathrm{a}}$ & $42.6^{a}$ & $26.5^{\mathrm{a}}$ \\
\hline Quartet-4N & 32.6 & $16.3^{\mathrm{b}}$ & $21.8^{\mathrm{b}}$ & $20.3^{\mathrm{ab}}$ \\
\hline SEM & 3.5 & 0.85 & 3.36 & 1.92 \\
\hline$P$ value & 0.613 & $<0.001$ & 0.007 & 0.040 \\
\hline
\end{tabular}


Table 2 Proportion of tillers of three AR1 infected perennial ryegrass cultivars grazed by adult or larvae Argentine stem weevil in 2007 and 2008.

\begin{tabular}{lcccc}
\hline & \multicolumn{2}{c}{$\%$} & \multicolumn{2}{c}{$\%$ teaves with adult feeding } \\
& 2007 & 2008 & 2007 & 2008 \\
\hline Aberdart-HSG & 1.7 & 26.7 & 13.3 & 8.3 \\
Samson-STD & 6.7 & 44.2 & 23.3 & 10.8 \\
Quartet-4N & 9.2 & 50.8 & 18.3 & 10.8 \\
SEM & 1.95 & 6.33 & 5.3 & 2.07 \\
P value & 0.069 & 0.066 & 0.449 & 0.688 \\
\hline
\end{tabular}

field trial, as compared to earlier published controlled laboratory trials.

\section{Argentine stem weevil damage}

Plots had received the high or low $\mathrm{N}$ application treatments 3 weeks prior to measurement but no effects of $\mathrm{N}$ application on ASW damage were detected. Large variance in adult and larval feeding also resulted in a lack of significance between cultivars (Table 2). Larval feeding was more prevalent in 2007 with the number of tillers affected ranging from $13-23 \%$ compared to only $8-11 \%$ in the following year (Table 2). Aberdart-HSG had the fewest tillers damaged. The feeding score of tillers damaged by larvae averaged 1.5 in both years.

There was a tendency $(\mathrm{P}<0.10)$ for adult weevils to avoid feeding on lamina of Aberdart-HSG. Adult feeding was highest in 2008 where weevils showed a preference for Samson-STD (51\% of tillers grazed) and Quartet4N (44\%) compared to Aberdart-HSG (27\%) (Table 2). Despite a strong presence of adult feeding, the average feeding score of 1.55 was relatively minor. In contrast, the previous year showed fewer tillers grazed by adults and had an average feeding score of 0.78 . The feeding score for Aberdart-HSG was 0.38 which was lower $(\mathrm{P}<0.05)$ than for Samson-STD and Quartet-4N which scored 0.90 and 1.07 respectively.

\section{Discussion}

There is increasing debate in the literature on the extent to which host grasses benefit from their association with foliar endophytes (see review in Rasmussen et al. 2006). Though resistance to insect pests is a widely accepted advantage in endophyte-infected $L$. perenne, the net value of the symbiosis/mutualism has been shown to depend on nutrient environment, (for $\mathrm{N}$ and $\mathrm{P}$ ) and shows much variation between individual host genotypes (Cheplick \& Cho 2003; Spiering et al. 2005). High sugar grasses and AR1 are both relatively new genotypic traits, and the association between the two is very recent $(c .<5$ years). The present study confirms how population level differences in plant genetic make-up (such as those inherent in a new cultivar) are sufficient to affect the outcome of the association.

Overall, endophyte concentration in Aberdart-HSG was $33 \%$ lower than in a standard NZ diploid cultivar, Samson-STD. This is in keeping with what was observed by Rasmussen et al. (2006), although, their study used HSG AberDove, and an EU diploid cultivar (Fennema) as the control. This suggests that (for a given level of ploidy) cultivars with high sugar content might in general have reduced endophyte content, though testing this is the subject of further investigation. The difference in endophyte content between HSG and control is lower here than in Rasmussen's study, but so too is the difference in sugar content. Based on Rasmussen et al. (2006), further reduction in endophyte level would be expected in plants with higher foliar $\mathrm{N}$ content. but the lack of effect of $\mathrm{N}$ application treatment on foliar $\mathrm{N}$ content during the periods in which endophyte concentration was measured, make this difficult to resolve under field conditions. On the first sample date (March 2007), N content of plants in both groups was relatively high (3\% $\mathrm{N})$ probably as a result of recent cultivation and mobilisation of soil N. Low $\mathrm{N}$ content at the second harvest (February 2008) may reflect a greater proportion of applied $\mathrm{N}$ in late summer/autumn becoming immobilised, resulting in a reduction in plant uptake (Cookson et al. 2001). Moreover, high clover content in the low $\mathrm{N}$ treatment may also have contributed to lack of differences between treatments in foliar $\mathrm{N}$ content. This reinforces the need for controlled studies, alongside field studies, to establish associations between nutrient supply and long-term consequences on the grass/endophyte association.

In conjunction with lower endophyte concentration in the HSG, peramine content was also lower compared with the standard. The relationship between peramine and endophyte content was not found to be as strong in this study compared to that seen by Rasmussen et al. (2006) which may be due to the greater variability in tissue ages and genotypes in a field study compared to a controlled laboratory one (Ball et al. 1997; Spiering et al. 2005). However, the expectation was that a grass cultivar/endophyte association that had lower peramine concentrations might mean reduced resistance to ASW (Popay et al. 2003). In the present study, the lower peramine concentration in the HSG did not appear to have exposed this cultivar to greater ASW damage. Indeed 
there were indications that the HSG/AR1 association is less susceptible to ASW attack than the standard diploid or tetraploid cultivar/AR1 combinations. This is counterintuitive, though it is likely that insect interactions with endophyte-containing plants may not depend on the alkaloid content alone (Rasmussen et al. 2008) but on the role of endophyte in altering the balance of other metabolites.

The concentration of peramine in the present study did not fall below the level of $0.1 \mu \mathrm{g} / \mathrm{g}$ which has been found to be the minimum level required to deter adults from feeding in artificial diet experiments (Rowan 1993). Concentrations in the sheath which deter larvae from feeding have been determined to be $10 \mu \mathrm{g} / \mathrm{g}$ (Rowan 1993). Although sheath peramine was not measured here, it is expected to be no less than levels in the leaf blade (Spiering et al. 2005) and so in our present study, was above the threshold for ASW deterrence suggested by Rowan (1993. See Table 1). However, the concern remains (from the indications of Rasmussen's study) that the HSG diploid cultivars might not be able to provide the same low level of susceptibility to ASW, as shown here, under $\mathrm{N}$ fertiliser regimes that create high $\mathrm{N}$ status in leaves and depress peramine concentrations further. Further field research is needed to confirm whether large $\mathrm{N}$ fertiliser applications in spring, might yet reduce endophyte content, and consequently peramine content, below a critical level.

In general the degree of feeding on the three AR1 infected cultivars was low, which is in keeping with the known efficacy of AR1 in resisting ASW feeding damage (Bultman et al. 2003; Gerard 2000; McNeill et al. 2007). We must not overlook that there are other factors that affect visiting by ASW adults, oviposition, and adult and larval feeding, in addition to cultivar/endophyte association (Barker 1989; Bell \& Prestidge 1999). But, overall, it is clear from the present study, the change in alkaloid or metabolite chemistry in the HSG/AR1 combination was not sufficient to critically reduce the cultivar's resistance to ASW, perhaps suggesting that other metabolites associated with HSG cultivars have an important role to play in susceptibility to ASW.

\section{REFERENCES}

Ball, O.J.P.; Barker, G.M.; Prestidge, R.A.; Lauren, D.R. 1997. Distribution and accumation of the alkaloid peramine in Neotyphodium lolii-infected perennial ryegrass. Journal of Chemical Ecology 23: 1419-1433.

Barker, D.J. 1989. Grass host preference of Listronotus bonariensis (Coleoptera: Curculionidae). Journal of Economic Entomology 82: 1807-1816.

Bell, N.L.; Prestidge, R.A. 1999. The effects of the endophytic fungus Neotyphodium starii on larval development of Listronotus bonariensis (Coleoptera:
Curculionidae). pp. 279-285. In: Proceedings of the 7th Australasian Conference on Grassland Invertebrate Ecology.

Bultman, T.L.; McNeill, M.R.; Goldson, S.L. 2003. Isolate-dependent impacts of fungal endophytes in a multitrophic interaction. Oikos 102: 491-496.

Cheplick, G.P. 2007. Costs of fungal endophyte infection in Lolium perenne genotypes from Eurasia and North Africa under extreme resource limitation. Environmental and Experimental Botany 60: 202-210.

Cheplick, G.P.; Cho, R. 2003. Interactive effects of fungal endophyte infection and host genotype on growth and storage in Lolium perenne. New Phytologist 158: 183-191.

Cookson, W.R.; Rowarth, J.S.; Cameron, K.C. 2001. The fate of autumn-, late winter- and spring-applied nitrogen fertilizer in a perennial ryegrass (Lolium perenne L.) seed crop on a silt loam in Canterbury, New Zealand. Agriculture, Ecosystems and Environment 84:67-77.

Edwards, G.R.; Parsons, A.J.; Rasmussen, S. 2007. High sugar ryegrasses for dairy systems pp. 307-334. In: Meeting the Challenges for Pasture-based Dairying. Proceedings of the 3rd Dairy Science Symposium

Gerard, P.J. 2000. Ryegrass endophyte infection affects Argentine stem weevil adult behaviour and susceptibility to parasitism. New Zealand Plant Protection 53: 406-409.

Goldson, S.L.; Proffitt, J.R.; Baird, D.B. 1998. The bionomics of Listronotus bonariensis (Coleoptera: Curulionidae) in Canterbury, New Zealand. Bulletin of Entomological Research 88: 415-423.

McNeill, M.R.; Hume, D.E.; Ashby, R.; Brandon, P.; Guscott, P.; Tosswill, B.; Barton, R. 2007. Ryegrass production in the Wairarapa, New Zealand: is biological control of Argentine stem weevil important? Proceedings of the 6th International Symposium on Fungal Endophytes of Grasses. Grassland Research and Practice Series 13: 301-306.

Popay, A.J.; Hume, D.E.; Davis, K.L.; Tapper, B.A. 2003. Interactions between endophyte (Neotyphodium spp.) and ploidy in hybrid and perennial ryegrass cultivars and their effects on Argentine stem weevil (Listronotus bonariensis). New Zealand Agricultural Research 46: 311-319.

Rasmussen, S.; Parsons, A.J.; Bassett, S.; Christensen, M.J.; Hume, D.E.; Johnson, L.J.; Johnson, R.D.; Simpson, W.R.; Stacke, C.; Voisey, C.R.; Xue, H.; Newman, J.A. 2006. High nitrogen supply and carbohydrate content reduce fungal endophyte and alkaloid concentration in Lolium perenne. New Phytologist 173: 787-797.

Rasmussen, S.; Parsons, A.J.; Fraser, K.; Xue, H.; Newman, J.A. 2008. Metabolic profiles of Lolium 
perenne are differentially affected by nitrogen supply, carbohydrate content, and fungal endophyte infection. Plant Physiology 146: 1440-1453.

Rowan, D.D. 1993. Lolitrems, peramine and paxilline: mycotoxins of ryegrass/endophyte interaction. Agriculture, Ecosystems and Environment 44: 103-
122.

Spiering, M.J.; Lane, G.A.; Christensen, M.J.; Schmid, J. 2005. Distribution of the fungal endophyte Neotyphodium lolii is not a major determinant of the distribution of fungal alkaloids in Lolium perenne plants. Phytochemistry 66: 195-202. 